\title{
¿Existe un pensamiento de nueva derecha en El Salvador?
}

\author{
José Marín
}

\section{En que consiste el pensamiento de la nueva derecha}

El pensamiento de la Nueva Derecha (ND) no es nuevo, pues su inserción data desde hace 30 años. En este tiempo ha incrementado sus áreas de influencia, pero es hasta la presente década en que se considera como un proyecto alternativo, por lo cual su publicidad y propagación es un fenómeno actual.

Al respecto, I.L. Horowitz, considera que el pensamiento de la Nueva Derecha en Estados Unidos se inicia como un proyecto ideológico que poco a poco va abarcando diversas fases, tanto ideológicas como económicas, lo cual es un elemento importante a destacar, ya que su proceso de maduración es relativamente largo, pero constante. Los elementos básicos que adopta para acrecentar su influencia en la sociedad norteamericana son: raciales, donde privilegia a la raza blanca; religiosos y los morales. Encuentra apoyo en las clases medias que adoptan con facilidad la ideologia de la Nueva Derecha.

Siguiendo a Platón, se considera que la Nueva Derecha es una predestinación biológica en el sentido de que la élite social es por sí misma la encargada de la conducción del Estado de acuerdo con una designación natural y no sociológica; propugna que el derecho de gobernar corresponde a la élite, por su ubicación actual e histórica de dominio.

La gestación del pensamiento de la Nueva Derecha tiene su fundamento en la fase educacional, cuyo programa contempla como as-

- Investigador del Centro de Investigación y Acción Social (CINAS) 
pectos principales la diferenciación precisa entre élite-masa, es decir, a los primeros se les prepara para mandar de manera "natural" y a los segundos a obedecer con "lealtad".

Para conseguir estos propósitos cuentan con bases intelectuales que sirven de apoyo para alcanzar las metas que se han trazado, es decir personal preparado para ejecutar funciones a su servicio. La Nueva Derecha rechaza ideologías que estén fuera de su concepción, pues consideran que su desarrollo conduce al nihilismo, es decir, la negación de toda creencia. Por tanto, manifiestan como necesidad indispensable que "el hombre debe estar gobernado por la emoción y no por la razón", este razonamiento es fundamental para disminuir la capacidad de reacción a los dominados frente a los "llamados a dominar", o sea a los abanderados de la ideologia de la Nueva Derecha.

En el aspecto económico productivo proponen cinco principios básicos: realismo, pragmatismo, productividad, eficiencia, rentabilidad, desaprueban formas productivas que no tengan relación con su realidad, en el sentido de que el mundo actual está dominado por recursos no renovables y por lo tanto deben ser aprovechados al máximo, sin desperdicios; es importante de destacar este punto, pues al contrario de lo que se afirmaba con anterioridad, cuando se reconocia que los recursos eran ilimitados, por lo que no importaba cuidarlos, para afirmar esto, es suficiente leer cualquier manual de economia, escrito antes de la crisis petrolera de 1973, donde se indicaba que la provisión de recursos no debia contemplarse dentro de la definición de economia, sino al contrario se daba poca importancia al aprovisionamiento.

Durante los últimos 17 años esta concepción ha cambiado de forma radical, en la actualidad se hace referencia a ciertos recursos naturales como finitos, se habla del deterioro ecológico, toma auge la ley de entropia, etc. Hoy en dia el acceso a los recursos no solamente se considera un elemento primordial en el análisis económico, y ha llegado a considerarse un elemento geoestratégico de primera importancia.

Dentro de esta nueva concepción cabe recordar el término Geopolítica, el cual como se aplica en la actualidad, difiere de las acepciones que tuvo en el pasado, asi, después de un largo periodo el término cayo en desuso, a partir de la derrota del nazismo prácticamente nadie habla de geopolítica, salvo en ciertos estados Sudamericanos donde le dan una connotación de seguridad nacional, entendiéndola como lucha anticomunista.

No es sino "a finales de la década de los años 70 (que) nuevamente recobra vigencia bajo una concepción estratégica diferente, aunque el 
término se encuentra estrechamente vinculado con el de seguridad nacional, pero ahora ligado sobre todo con cuestiones estratégicoeconómicas de las grandes potencias. Anteriormente el énfasis se centraba en el campo estrictamente militar con predominio del uso y demostraciones de poder, en la actualidad con la nueva concepción lo que se pretende es asegurar el abastecimiento de energéticos y minerales estratégicos, como estos no necesariamente se encuentran localizados al interior de un Estado-Nación, sino en otros lugares, por tanto, aspectos que tienen que ver con su ubicación geográfica, sus vias de transporte, su accesibilidad política, su seguridad militar, son motivaciones que deben tomar en cuenta los Estados que requieran de dichos recursos"1. El razonamiento anterior tiene lógica pues no solamente los recursos considerados estratégicos son finitos, no renovables de ahi que hay necesidad de asegurar su suministro 0 al menos su acceso, es decir, estamos en presencia de un mundo distinto en su concepción, pues antes no se tomaba en cuenta la escasez de recursos, es más estos eran considerados como un dato no una variable.

En el aspecto económico la Nueva Derecha es realista, pues ahora se priva la "maximización restringida" y no como lo hacía la teoria económica tradicional donde la maximización era sin restricciones.

Por otra parte el "realismo" de la Nueva Derecha, en el campo económico se refleja en el hecho de "reconvertir" el aparato productivo, que implica utilización de nueva tecnología para hacerlo más efectivo; así como lograr la privatización del aparato productivo pues consideran que las decisiones en materia de producción deben ser económicas y no politicas, como serían las que adopta el Estado cuando tiene a su cargo sectores productivos. En otras palabras, abogan por una disminución del Estado-productor, ya que las decisiones estrictamente económicas deben estar cenidas por las leyes económicas y éstas sólo pueden ser adoptadas por el sector privado.

Además, la Nueva Derecha considera que el sector tradicional productivo es ineficiente, pues al ser conservadores privilegian 10 "viejo conocido" sobre las nuevas modalidades productivas, lo consideran reacio al cambio y las innovaciones, pues el cambio es contrario a sus intereses, es por eso que la Nueva Derecha considera a los sectores tradicionales contrarios al progreso, y sujetos obsoletos que se encuentran incapacitados de comprender que sin la aplicación de los cinco principios básicos que proponen, no se puede alcanzar la eficiencia necesaria para aprovechar al máximo los escasos recursos que se disponen.

Los cambios que se han venido operando en la correlación de fuer- 
zas de los diferentes sectores que conforman el producto bruto son indicativos de que los sectores considerados "promotores" del progreso, como han sido el primario y secundario, han perdido dinamismo y por tanto importancia dentro de la generación de bienes y servicios; si estos sectores han perdido importancia, esta ha sido reasignada al sector terciario, que esta logrando imponerse como fundamental en la estructura del producto bruto, situación manifiesta en la crisis de la presente década que ha sido percibida por la Nueva Derecha que la esta aprovechando para lanzar su estrategia, convencida de que la reacción que tendrán los sectores tradicionales a sus planteamientos tendrá menos fuerza y, por lo tanto, consideran que es el momento clave para lanzar su ofensiva ideológica y así desplazar a la vieja derecha. El hecho de que el sector terciario haya pasado a ser el principal to hace desde una posicion sumamente ventajosa, pues ha logrado una cierta autonomia económica respecto del resto de sectores, es decir que su empuje y acción no están delimitados por los otros sectores, sino que, en cierta medida, tiene capacidad propia para crecer, pero no solamente eso, sino que el sector primario y secundario se vuelven en cierta forma dependiente del terciario, en cuanto a comercialización, comunicaciones y todo lo que implica el aspecto financiero.

Asimismo dentro de su esquema de penetración, la Nueva Derecha se ha propuesto llegar a ser la fracción dominante en el sistema capitalista, destaca que su lucha no es política, en el sentido de buscar el control directo del Estado sino que éste sea portador de dicho esquema; además no busca el control de partidos politicos y sindicatos, y en contradicción se opone a ellos por considerar que atentan contra un principio esencial que propone "la desigualdad es algo inherente al sistema", de alli que tanto el Estado, los Partidos tradicionales y los sindicatos actuales, propugnan por la igualdad de los hombres, lo cual contradice al esquema de la Nueva Derecha. Como los sindicatos no pueden cambiar su función, hay que ignorarlos, pero ciertos partidos pueden ser influenciados directamente a través de la ideología, pero en forma indirecta a través de personeros representativos de la Nueva Derecha, basta con que los partidos sean portadores de esta nueva ideología, en el caso de otros partidos que no puedan ser influenciados, proponen ignorarlos porque al fin de cuentas se les impondrá un esquema al que tendrán necesariamente que adecuarse. Ya que consideran que al final todos deberian tener "fidelidad ideológica" con el discurso de la Nueva Derecha.

Descrita a grandes rasgos to que es la estrategia de la Nueva Derecha, se hace necesario preguntarse, para el caso que nos preocupa, que es la sociedad salvadorefia si existen en su seno los postulados de 
la Nueva Derecha, este será el contenido de la siguiente parte del trabajo.

\section{Hacia un pensamiento de nueva derecha en El Salvador}

Para comenzar este punto se hace necesario una breve descripción de las diferentes posiciones que tienen en este momento los distintos sectores de la Derecha Salvadoreña, para ver si alguno de ellos es portador de la estrategia de la Nueva Derecha.

\subsection{La Asociación Nacional de la Empresa Privada (ANEP)}

Sus posiciones declaradas son representativas de viejos esquemas tradicionales, en un pronunciamiento público aparecido el 27 de julio de 1987 dejan entrever cual es su percepción sobre la problemática salvadorefia, la que describen asi: "La situación es extremadamente explosiva y pone en peligro la institucionalidad de la República y la seguridad de la población salvadoreña... Desde 1979 los dirigentes gubernamentales se han caracterizado por su tolerancia con los grupos antisociales y han actuado en forma débil y confusa y es esta actitud la causa principal del desenfreno, el libertinaje y la impunidad con que actúan los marxistas-leninistas". Para ponerle freno a la situación le exigen al gobierno que actúe con energía para restablecer el orden, para ello propone lo siguiente:

- Respeto absoluto de la Constitución.

- Que el Estado desactive su política de "lucha de clases", la cual la entienden en que el Estado, y concretamente la democracia cristiana, promueven la lucha de clases al fomentar la división de la sociedad, pues el lenguaje que utilizan al referirse a los sectores productivos es hostil, ya que al emplear términos tales como "oligarquía económica" fomenta la división, pero además consideran que la propaganda oficial que cataloga a los empresarios como enemigos del pueblo propicia la generación de actitudes hostiles de los sectores laborales.

- En el campo económico que se deje atrás la nacionalización de amplios sectores productivos, en cierta medida dejan entrever que el reformismo es perjudicial y que su deseo es volver a los esquemas del pasado, al que consideran que fue mejor.

- En el campo social mencionan que el progresivo deterioro de la economía nacional impide también el desarrollo de programas que tiendan a mejorar las condiciones sociales del pueblo salvadoreño. 
Se subraya lo anterior por considerarlo como una propuesta que, de alguna forma, se reivindica a un "estado de bienestar", pero descansando en que "la estructuración de una política de mejoramiento para todos los salvadorefios debe hacerse con un alto sentido de responsabilidad patriótica. La forma más segura y práctica de poder mejorar integralmente a nuestro pueblo, es estimulando a la Empresa Privada para que genere riqueza y que todos los beneficios de la economía lleguen a todos los salvadorenos, sin distinciones de ninguna naturaleza... Deben hacerse a un lado los experimentos sociales fracasados que han hundido a nuestro país en la peor crisis política, económica y social de su historia. Ha llegado el momento de ver las cosas sin prejuicios ideológicos, teniendo como objetivo la reconstrucción de nuestra Patria."

De las consideraciones que hace la ANEP, podemos deducir que difícilmente se acomodan al planteamiento de la Nueva Derecha, es más podemos avanzar que en sus planteamientos son ante todo representativos de las posiciones de la Vieja Derecha, a la cual se opone la Nueva Derecha. $Y$ es más la ANEP en su seno tiene a los sectores más recalcitrantes, por no decir a la tradicional oligarquia terrateniente que siempre se ha opuesto a cualquier esquema de modernización del aparato productivo nacional, baste recordar la ofensiva que lanzaron en 1976 con ocasión de la promulgación del primer distrito de transformación agraria que propuso el gobierno del coronel Molina, al que combatieron tajantemente, llegando incluso a hacer que el gobierno retrocediera en su propuesta a pesar de que habia dicho que la implementación de la transformación agraria era el "seguro de vida" para el capitalismo en El Salvador y que se hacia indispensable modernizarlo.

En la actualidad, trece años después del fracaso del gobierno de Molina, la posición antimodernista de la ANEP no ha cambiado en lo absoluto, pues consideran que las reformas implementadas por la democracia cristiana son "experimentos socialistas" y no de modernización.

\subsection{La Cámara de Comercio e Industria de El Salvador}

En un pronunciamiento aparecido el 25 de febrero de 1987, dejan entrever sus posiciones. Le achacan al mal manejo de la economía que el actual gobierno, como la causa principal de los grandes problemas económicos y sociales por los que atraviesa EI Salvador.

La coincidencia que manifiesta la Cámara de Comercio e Industria en sus posiciones son sorprendentes si se comparan con las expresadas 
por la ANEP, de alli que lo que se dijo para el caso de la ANEP sea aplicado para la Cámara.

\subsection{Los Partidos de Derecha (ARENA, PAISA, PPS, LIBERACION, y otros minoritarios)}

Son partidos representativos de diversas fracciones de la burguesia, por lo que cada uno de ellos defiende las posiciones e intereses de sus representados, da la casualidad de que el "minimo común denominador" que tienen respecto a los cambios estructurales emprendidos por la democracia crisitiana, es el ataque a dichas medidas por considerarlas socialistas, si algún nombre común se les puede poner, de ahi que hay que impugnarlas, para de alguna forma "regresar al pasado" al que califican como mejor.

En un sentido amplio se puede afirmar que tanto los grupos corporativistas de la empresa privada como los partidos de derecha manejan el mismo discurso, antimodernizante, antireformas, antidemocristiano, con un recuerdo que el pasado fue mejor.

La identidad de planteamientos de los grupos corporativos de la empresa privada con los de los partidos políticos de derecha, nos indica que la empresa privada ahí representada contraviene uno de los postulados básicos de la Nueva Derecha, como es el de no copar directamente el espacio de los partidos, sino inculcarles el planteamiento de la Nueva Derecha, por tanto el hecho de que en El Salvador exista una simbiosis entre los planteamientos reivindicativos de los grupos corporativistas de la empresa privada, con los planteamientos de partidos políticos, es muestra fehaciente de que se está en presencia del viejo esquema de participación política de la burguesía con el que no concuerda la Nueva Derecha. Destaca el hecho que entre las personas más representativas de los partidos existan prominentes miembros de familias de arraigo oligárquico.

Por si quedara alguna duda de la simbiosis que existe entre los grupos corporativos de la empresa privada con los partidos de derecha, principalmente con ARENA, los sucesos y declaraciones posteriores a las elecciones del 20 de marzo de 1988 lo corroboran. Cuando se tenia la incertidumbre de que si ARENA, después de afirmar, que según datos extraoficiales, tenía 35 diputados (Diario de Hoy, 1a. página, 22 de marzo, 1988), comenzó a dar cifras menores de diputados a su favor 33. hasta llegar a 31 y afirmar que ese es el número definitivo. Cuando el Consejo Central de Elecciones dijo que revisaría las actas electorales de algunos departamentos, se desató la ofensiva de la ANEP y los partidos (ARENA, PAISA y LIBERACION) calificando de maniobra traudulenta 
antidemocrática la medida adoptada.

La ANEP amenazó con convocar a un paro de actividades,si se llega a producir el fraude en los escrutinios (Diario de Hoy, 24 de marzo, pág. 3) siguiendo la experiencia del 22 de enero de 1987, y se declaraba en estado de emergencia a partir del 25 de marzo, afirmando que "ANEP se mantiene vigilante $y$ atenta frente a las anomalías que se están dando en el escrutinio final de diputados, para usurparle la mayoría absoluta que ha ganado el partido ARENA y reafirma su posición de respaldar totalmente a los dirigentes de los partidos políticos de la oposición, en aquellas acciones de carácter civico que sean necesarias tomar para detener un fraude electoral".

La posición de ANEP no puede calificarse como defensora del respeto a la voluntad popular expresada en las urnas, pues en anteriores procesos electorales cuando se evidenció el fraude (1972-1977), la asociación permaneció callada.

Se puede afirmar, aunque no en forma exhaustiva, que la derecha corporativa y su expresión política a través de partidos, son excluyentes de las posiciones de la Nueva Derecha, y es más, se puede también decir, que de acuerdo con la Nueva Derecha, serian ellos sus principales enemigos por oponerse a la modernización, aunque para el caso salvadorefio, debido a la situación de conflicto existente, tanto la vieja derecha como el movimiento insurgente son enemigos a vencer, aunque el esquema que se utilice para cada uno de ello sea totalmente diferente.

Asi tenemos que para derrotar al movimiento popular, puede hacerse por medio de una victoria militar o bien a través de una solución politica, para el primer caso, las explicaciones de como se impondría el esquema de la Nueva Derecha salen sobrando, pues al derrotado militarmente no le queda otra opción que aceptar las decisiones del vencedor; mientras que para la segunda opción la situación difiere diametralmente, pues lo que se trataria de imponer mediante una salida politica seria la predominancia ideológica del pensamiento de la Nueva Derecha y hacer que la izquierda se acople a dicho esquema, sin profundizar mucho en dicha posibilidad, es probable que esa sea la respuesta por la que la Nueva Derecha salvadoreña estaría, es decir privilegia una salida política sobre una estrictamente militar, ya que los costos de reconstrucción se reducirian y su proceso sería sobre una base de consenso.

Se ha dicho cual es la posibilidad de derrotar al movimiento popular mediante el esquema de la Nueva Derecha, pero cuál seria la otra para neutralizar a la vieja derecha, en ese punto vale la pena recordar que ya se han dado pasos al respecto,en primer lugar destacan las reformas 
implementadas a partir de 1980, la siguiente cita es ilustrativa al respecto "los mismos Estados Unidos reconocen como uno de los elementos generadores de la caótica situación salvadorena, al exagerado poder concentrado en la oligarquía y que por tanto debe ser desmantelado (ese poder) para que El Salvador garantice su viabilidad como nación hacia el futuro, pero dentro del sistema occidental, dicho aspecto nos vendría a confirmar la validez de la hipótesis de que el golpe de octubre de 1979 se realizó con el objeto de quitar del bloque en el poder a la oligarquia, para asi modernizar el capitalismo salvadorefio.. no obstante su intransigencia ante los movimientos de liberación popular para los Estados Unidos es necesario realizar una serie de reformas para garantizar la modernización económica"2.

Al mismo tiempo dentro de la economia salvadorefia se han venido operando una serie de transformaciones que nos permiten deducir que efectivamente los sectores tradicionalmente poderosos han perdido hegemonia dentro del aparato económico. Se asiste a un proceso de deterioro del poder económico basado en la tenencia de la tierra asi como del sector industrial, los siguientes datos son ilustrativos al respecto "para los años que van de 1971 a 1978, el movimiento total de excedente intersectorial ascendió a 1.144 .94 millones de colones, que se distribuyeron asi entre los sectores económicos: agropecuario $26.1 \%$, comercio $67.1 \%$, construcción $19.13 \%$, financiero $1.3 \%$, propiedad de vivienda $3.5 \%$, por su parte el subsector café recibió el sólo 1303.14 millones de colones, total superior al trasladado o recibido por cualquier sector por si solo, (los datos se refieren a traslados sectoriales de excedente generado por la heterogeneidad de tasas de inflación que afectan a los diversos sectores). Mientras que para el periodo comprendido entre1979 a 1985, la situación cambia profundamente, el traslado del excedente ascendió a 2235.28 millones de colones, de los cuales el comercio recibió $92.0 \%$, la propiedad de vivienda $3.2 \%$, y, los servicios personales $4.8 \%$. Por su parte el subsector café, que en el periodo anterior habia superado al comercial, para éste que estamos considerando ha sido superado por el comercio, actividad que a la vez ha pasado a comandar la economía, colocándose en la década de los 80 como el principal sector generador de bienes y servicios dentro de los esquemas de contabilidad nacional que se aplican en EI Salvador's.

No solamente este aspecto es necesario destacar, sino también es importante recordar que el sector comercio, para poder llevar adelante un proceso acumulación ha logrado una relativa independencia de los sectores tradicionalmente dominantes, asi tenemos que buena parte del poder adquisitivo que tiene la población salvadoreña es totalmente independiente de lo que esté aconteciendo en el sector productivo, en 
este punto estamos haciendo referencia a las ayudas unilaterales que está recibiendo la economía salvadoref́a provenientes del extranjero, donde destaca la ayuda de Estados Unidos, que ha llegado a equipararse, con el presupuesto de la nación (se ha recibido en 1987 por lo menos 750 millones de dólares), por otro lado, se encuentran las ayudas familiares que envian los salvadoreños residentes en el extranjero, principalmente en Estados Unidos, que según diversos cálculos es una cifra que oscila entre un minimo de 650 y un máximo de 1.300 millones de dólares, entre los dos tipos de entradas de dólares nos encontramos que representan aproximadamente el $40 \%$ del producto bruto generado para 1987, cifra que deja en total desventaja al tradicional café que apenas está representando el $12 \%$ del PTB, es decir, que ha sido totalmente desplazado como actividad principal, de ahí que incluso hasta su influencia política también se ha visto disminuída, en otras palabras se ha logrado que pierda parte de la influencia política que tuvo en el pasado, efectivamente el poder oligárquico ha descendido pero no se ha eliminado, lo cual viene a representar un logro de ciertos postulados de la Nueva Derecha en El Salvador.

\subsection{La Fundación Salvadoreña para el Desarrollo Económico y Social (FUSADES)}

En los párrafos anteriores hacemos alusión en forma explícita, aunque no definida, de que existe un movimiento de nueva Derecha en El Salvador, si bien esto es una posición que le resta coherencia al presente trabajo, pues como es posible hablar, y además ser determinante con la existencia, de un movimiento de Nueva Derecha. Sin antes haber evidenciado de que efectivamente existe un movimiento tal en EI Salvador y que además parece que ya tiene alguna fuerza, y no solamente eso, sino que ya está aplicando parte de su esquema incluso desde posiciones de gobierno, sin que esté precisamente en el poder gubernamental.

En las siguientes líneas se tratará de subsanar este error dentro del esquema del trabajo, pues se considera que es FUSADES la institución que tiene mayor identificación con los postulados de la Nueva Derecha.

Las razones que esgrimimos para afirmar lo anterior derivan del hecho de que FUSADES es el único organismo empresarial que no se presenta en forma corporativa, sino a través de una fundación promotora del desarrollo, en este punto vale la pena adelantar que ha sido el único organismo empresarial que proyecta un nuevo esquema de desarrollo que lo han denominado "la necesidad de un nuevo modelo económico para El Salvador", en el que se opone a la realidad pasada 
al mencionar que la perspectiva futura de desarrollo no puede descansar ni en la agroexportación ni en el modelo sustitutivo de importaciones porque ya mostraron su inviabilidad en El Salvador, como via alternativa proponen que el eje de desarrollo debe descansar en un modelo de crecimiento hacia afuera, sobre la base de que las exportaciones no tradicionales dinamicen a la economía.

Como base a su propuesta, mencionan que El Salvador debe aprovechar al máximo la ventaja comparativa de que dispone, y ésta no es más que la abundancia de mano de obra que además es altamente eficiente, al mismo tiempo son pragmáticos al indicar que los anteriores modelos han ocasionado serias distorsiones en el mercado de factores, ya que privilegiaron una industrialización de invernadero al abaratar, políticamente, el factor capital para asi favorecer la industrialización, esto provocó que relativamente el capital fuera más barato que la mano de obra, de ahí que no se aprovechara al máximo la gran disponibilidad del factor humano que se tiene, lo cual ha generado su desaprovechamiento, ocasionando gran presión para el desempleo, por lo tanto en su propuesta resalta el hecho que es indispensable eliminar esta distorsión que se ha dado en el mercado de factores.

También son los únicos que no han emprendido una campaña desestabilizadora contra el régimen democristiano, al contrario han tratado de venderle la idea del modelo que proponen, como apoyo a esto vale la pena mencionar que Napoleón Duarte visitó las instalaciones de FUSADES el pasado 24 de abril de 1986, donde se le dió a conocer la Filosotia de la Fundación y las actividades que desarrolla, la respuesta de Duarte fue de complacencia ante el esfuerzo que FUSADES realiza, ya que a criterio de él, están poniendo al servicio de la nación la capacidad empresarial salvadoreña, al mismo tiempo manifestó su aceptación al Modelo Económico propuesto por FUSADES, al señalar que tiene gran contenido no solamente económico sino social y que se necesita de que todos participen para hacerlo realidad y además viable. Por otra parte, Duarte manifestó, en su visita, sus amplias coincidencias con el anteproyecto de ley de fomento para las exportaciones que ha elaborado la Fundación.

Hasta el momento no se ha identificado a FUSADES, con ninguno de los partidos políticos existentes. ¿Entonces cuál es el canal que están utilizando para promover su propuesta? Su penetración no descansa en los medios que tradicionalmente se usan en El Salvador, ellos están haciendo una labor muy destacada en el aspecto formativo de una gran cantidad de empresarios y diversos sectores. Haciendo un balance de sus actividades encontramos las siguientes: 
- Conferencia a la Asociación Salvadoreña de Ingenieros Mecánicos, Eléctricos e Industriales y a la Asociación de Ingenieros Quimicos, sobre el papel de FUSADES en el desarrollo económico del país.

- El inicio de un plan de capacitación para técnicos en maquila de ropa, que se desarrolla en Atlanta, Estados Unidos que dará cobertura a unos 80 técnicos en total.

- Cursos de capacitación para artesanos, entre los que destacan elaboradores de hamacas, y artesanos de La Palma.

- Programa de capacitación para jóvenes salvadoreños, que se encontraban estudiando carreras universitarias en Estados Unidos .

- Estudios sobre diversificación agricola.

- Organización de una conferencia sobre política exterior norteamericana, impartida por un miembro del Centro Roosevelt para Estudios de Política Norteamericana en Washington.

- El establecimiento de un programa de formación técnica para detectar áreas prioritarias que necesiten capacitación, especialmente en el sector industrial, para ello cuentan con el apoyo de la Asociación Salvadorena de Industriales (ASI).

- La realización de un seminario sobre acuacultura para incentivar y capacitar técnicamente a unos 140 participantes sobre el cultivo de camarón para exportación.

- La instrumentación de un programa con la Unión de Dirigentes de Empresas Salvadoreñas (UDES) para explicar como funcionan los mecanismos de politica monetaria y crediticia, que sirva para fomentar el acercamiento entre las autoridades de la oferta monetaria, los encargados de canalizarla y el usuario; modificar o eliminar positivamente percepciones equivocadas que existen entre los sectores referidos.

- La firma de un convenio de cooperación con el AID para dar inicio al Programa para la Promoción de la Pequeña y Microempresa (PROPEMI).

- La creación de la Corporación para Riego y Exportaciones Agricolas (CORPRE), que tiene el objetivo de fomentar cultivos agricolas no tradicionales que utilicen irrigación, así como establecer plantas procesadoras para esos productos.

- Actividades de asesoramiento con diversas entidades, como son la Cámara de Comercio e Industria de El Salvador, la Sociedad de 
Comerciantes e Industriales Salvadorefios, la Asociación Salvadorefía de Empresas de Maquiladoras, así como con la ASI, ANEP, COEXPORT, PROLECHE, etc.

\section{- Etcétera.}

En el listado anterior, que ha sido tomado de la Carta Informativa de FUSADES, destaca la gran cantidad de actividades que realizan, asi como su diversidad que prácticamente abarcan a todos los sectores.

Sorprende la cantidad de cursos de capacitación con todas las asociaciones corporativas de la empresa privada tradicional, que sin manera de equivocarse son para promover con ellos su modelo alternativo que han propuesto, el cual analizaremos más adelante, porque nos dá más elementos de juicio para indicar que es portador de la ideologia de la Nueva Derecha.

En relación con esto, el CINAS considera que "FUSADES se ha transformado progresivamente en un centro aglutinador de inteligencia empresarial, más que en una estructura corporativa tipo Cámara de productores, constituye un centro elaborador de diagnósticos, análisis y recomendaciones, ...que promueve abiertamente un nuevo modelo para el país. Desarrolló una fuerte crítica al modelo de sustitución de importaciones causante estructural, en su opinión, de muchos de los problemas del capitalismo salvadorefio: a decir de FUSADES, la crisis, en sus diversas dimensiones, puso de manifiesto el agotamiento del modelo de crecimiento seguido por el pais, basado en la agroexportación de unos cuantos productos y en la sustitución de importacioens dentro del marco del Mercado Común Centroamericano y se manifiesta partidario de un modelo que denomina de diversificación de exportaciones, que permitiría abrir un abanico de exportaciones no tradicionales que transformaria a El Salvador en un Taiwan o una Corea del Sur". Asimismo sefiala que a diferencia de los grupos corporativistas de la empresa privada, los pronunciamientos de FUSADES son eminentemente económicos y están traspasados por una idea general de modernización productiva para el pais. Muchos han querido interpretar esto último como que la ausencia de criticas directas al gobierno y su pretensión modernizante, son elementos que permitirian que FUSADES podria servir de puente buscado por el PDC con el sector privado4

Tanto "la democracia cristiana como FUSADES, se reivindican así mismos como modernizantes, pero cabria preguntarse respecto a qué pasado tradicional. En el caso de la DC la pretensión modernizante está referida a la crítica de la sociedad oligárquica, en particular a los terratenientes. En cambio FUSADES realiza su crítica al pasado to- 
mando como referencia el proyecto de sustitución de importaciones... es posible sostener que en FUSADES se gesta embrionariamente un proyecto de reorganización capitalista para El Salvador que implicaría una sustantiva modernización de su estructura productiva, la que permitiria una consolidación de las clases dominantes lo que no niega que ello pueda significar la subordinación de los intereses particulares de alguna de sus fracciones"5.

\section{El modelo económico para El Salvador propuesto por FUSADES}

El documento sale a la luz a finales de 1985 y se elabora un programa de presentaciones que incluye a todos los sectores del país. En la introducción del documento dejan claro que constituye un aporte para crear conciencia y formar opinión en las personas interesadas en el desarrollo de la economía y que participan, a todos los niveles en el diseño, planificación y ejecución de la política económica. Desde el primer momento especifican que lo que pretenden es formar conciencia consensuada sobre la necesidad de que se implemente el proyecto, por ningún lado lo presentan como una plataforma programática.

A la vez señalan que "el modelo propuesto tiene al hombre como principio y fin. Su propósito, según ellos, es alcanzar un sistema económico eficiente... el fin ulterior del modelo es que el hombre realice sus aspiraciones físicas, sociales, intelectuales y económicas. El hombre, además de ser el principio del modelo, es igualmente su motor. En este punto son sumamente coincidentes con los postulados de la Nueva Derecha porque toman como sujeto al individuo, desprovisto de cualquier forma de organización.

También muestra un cierto grado de realismo al indicar que se basa en la objetiva identificación de las necesidades, posibilidades y limitaciones del país. Al promover las exportaciones no tradicionales presuponen que la producción nacional sea capaz de competir, en condiciones de calidad y precio, en el mercado internacional y que esto se va a lograr mediante una estructura productiva eficiente, nada más coincidente con las propuestas de la Nueva Derecha. Asimismo sefialan que la participación del gobierno en la política económica debe adecuarse a las condiciones del mercado, es decir, que no intertiera en las decisiones económicas, salvo en aquellos renglones que sirvan para cubrir necesidades vitales de la sociedad que dificilmente pueden satisfacerse a través del mercado, en otras palabras están por minimizar la presencia económica del Estado.

Ellos abogan por un realismo en las relaciones económicas que 
incluyen los siguientes aspectos: eliminación de tasas de cambio sobrevaluadas, de las tasas de interés subsidiadas, de una política salarial que refleje la productividad de la mano de obra, por tanto que desaparescan los salarios mínimos, que se elimine el proteccionismo, porque disloca el mercado interno en factores al abaratar políticamente al capital.

Se pronuncian porque la clase trabajadora sea "leal" al nuevo modelo, esto se aprecia cuando se afirma en el documento que se debe promover la generación masiva de empleo y un clima de armonía en las relaciones laborales, a la par de un ambiente de disciplina social, cuyo objetivo común sea la eficiencia económica.

Al mismo tiempo presentan una crítica a los modelos implementados anteriormente, cuando afirman que se debiera reconocer que la naturaleza, profundidad y duración de la crisis que actualmente afronta la economia salvadoreña, se debe en gran parte, al reflejo de sus propias características que no han podido ser modificadas porque se ha carecido de un modelo económico en el que las necesidades de crecimiento sobre bases sostenidas sean compatibles con las posibilidades reales. En otras palabras, que la crisis es el resultado de la acumulación de viejos problemas estructurales económicos que nunca fueron resueltos en el pasado.

Dentro de las caracteristicas que debe tener el nuevo modelo proponen que se debe aprovechar al máximo la fuerza laboral existente y que al tomar en cuenta la productividad de la mano de obra se permitiria aumentar el rendimiento de la misma a niveles que hagan competitiva la producción del pais en los mercados internacionales, y que esto supone una clase empresarial eficiente capaz de emplear aquellas tecnologías que hagan posible una mayor productividad. En este punto son claros en indicar que solamente aquella clase empresarial que se adecúe a las condiciones nuevas puede prosperar, dejando entrever que los que no innoven están condenados al fracaso. Para posibilitar esto se requiere del concurso del Estado, quien debe conceder el liderazgo a los sistemas empresariales.

Cuando se refieren a los requisitos que consideran necesarios que se den para poder hacer andar el modelo, muestran una gran claridad en sus planteamientos, aqui sorprende cuando afirman que debe darse una voluntad política para poderlo implementar y alirman que es indispensable que el Gobierno de la República, después de ponderar el modelo, decida tomar todas las medidas posibles para ponerlo en práctica, de ahi que el Gobierno seria, por lo tanto, el promotor y facilitador del nuevo modelo. 
En este punto vale la pena detenerse un poco, pues lo que no dice es más importante que lo que dice. Del planteamiento se deduce que ellos no están por conseguir el poder político para llegar a implementarlo, como son las posiciones de la vieja derecha que siempre ponen por delante el control gubernamental para poder implementar sus modelos; en la presente propuesta eso no es necesario, sino que basta con que el gobierno, independiente de que si es la DC, ARENA o incluso la izquierda misma, no pueden rechazar el modelo propuesto, porque según ellos es la única alternativa posible que le queda a El Salvador, es decir que su implementación depende de la fórmula de consenso que se logra en torno a él. Asimismo consideran como requisito indispensable el crear las condiciones propicias para que vuelva la armonia a la sociedad, con el fin de desarrollar la mistica necesaria alrededor del esfuerzo nacional que entraña el logro efectivo de los objetos del modelo.

Es esencial, restablecer la institucionalidad y promover un respeto permanente a las leyes, al mismo tiempo sefialan que no pueden continuar prevaleciendo la polarización y las divisiones políticas.

Como se puede ver la propuesta de FUSADES, a diferencia de los planteamientos que hacen las organizaciones corporativas de la empresa privada así como de sus respectivos partidos que velan por sus intereses, carece de expresiones de oposición al gobierno, y mucho menos que la democracia cristiana debe ser eliminada, se intuye que para FUSADES cualquier gobierno puede llevar adelante este esquema, de ahí que no estén por el acceso al poder. Pero al mismo tiempo sorprende que la campaña de divulgación que tiene FUSADES de sus planteamientos, no descrimina a nadie, o si no véase la lista de actividades que han realizado, que pareciera que aquellos sectores a los cuales no les ha sido presentado el modelo es por autoexclusión de ellos mismos y no por una política deliberada de FUSADES.

Al mismo tiempo queremos destacar que FUSADES, ha abierto una oficina en Nueva York, de acuerdo al contrato firmado con Arthur Young and Company, el propósito de la oficina es que sirva de apoyo al programa de Promoción de Exportaciones (PAIDEX) que tiene la fundación, sorprende al mismo tiempo que las oficinas están localizadas en la zona más céntrica de Nueva York.

\section{Los programas de FUSADES}

En relación a la propuesta que hace FUSADES sobre aprovechar al máximo el exceso de mano de obra, se tiene que ésta es altamente productiva, ya que siempre ha habido indices elevados de desempleo y subempleo combinados; además la relación existente entre el pago al 
factor productivo trabajo y capital (salario/interés) ha sido desequilibrada por factores politicos dado que históricamente se ha abaratado al capital con tal de conseguir un proceso de industrialización que nunca logró ubicarse como el principal rubro dentro de la composición del producto bruto, ni mucho menos servir de arrastre hacia otros sectores, para lograr indices altos de crecimiento económico.

Por lo tanto la relación Salario/Interés (S/i) es más alta de lo que debiera, lo que ha permitido que el capital sea, en términos relativos, más barato que la mano de obra, por lo cual se privilegia el uso del capital por sobre la mano de obra, produciendo más desempleo de lo normal.

Asi pues, la propuesta de FUSADES pretende dar un tratamiento más "real" a la dotación de factores con que cuenta la economía salvadorefia, por lo que se espera, de acuerdo con su puesta en marcha, que se produzca un encarecimiento relativo del capital y una mayor demanda de mano de obra debido a que relativamente será más barata de lo que hasta ahora es, de ahi que también se tendrá que generar una situación en que los procesos productivos tendrán más componente de mano de obra que de capital, en comparación con la situación prevaleciente en la etapa anterior.

La producción que se origine bajo este esquema tendrá como destino o mercado principal el externo, combinado con esto la consecuencia que traerá dentro de sus esquemas, será la solución de los principales problemas económicos que FUSADES identifica como: la falta de divisas y el aumento de los índices de desempleo ${ }^{6}$. Pero el énfasis en lo que se debe producir debe recaer en aquellos produclos exportables considerados como no tradicionales, to que conduciria a una diversificación en la estructura de exportación, sin que desaparezcan los productos que tradicionalmente han sido los principales (café, algodón, azuicar y camarón), esto con la finalidad de que el sector externo sea menos vulnerable al vaivén de los precios internacionales.

El funcionamiento del modelo y su lógica, de acuerdo con Rafael Rodriguez Loucel, es descrito de la siguiente manera: "el modelo de exportaciones debe interpretarse como un impulsador del desarrollo interno del país, que favorecerá a todos los sectores, ya que al exportar más, se van a generar divisas que permitan al pais importar materias primas y bienes de capital para generar un proceso productivo orientado hacia el mercado interno; si hay mayor producción tanto exportable como orientada al mercado interno, se generará más empleo, lo que a su vez generará más ingresos que generan más demanda y el mercado interno se amplia. Las exportaciones vienen a ser la fuente impulsora de 
la economía del país"?.

Hasta este punto, se puede afirmar que el modelo propuesto, en lo que respecta a los sectores que serán los que dinamicen el desarrollo del pais, no difiere con el desarrollado por el Ministerio de Planificación realizado en 1984 bajo el nombre de "Bases metodológicas para la elaboración del plan de desarrollo 1985-1988".

A nivel de modelística, el proyecto de promoción de exportaciones no tradicionales se podria simplificar con la siguiente fórmula:

$$
\frac{\Delta \text { Xnt }}{\text { Xnt }}>\frac{\Delta \text { Prod. Ind. }}{\text { Prod. Ind. }}>\frac{\Delta X}{X}>\frac{\Delta \text { PTB }}{\text { PTB }}
$$

Donde $\Delta X n t / X n t$, corresponde a la tasa de crecimiento de las exportaciones de bienes no tradicionales.

$\Delta$ Prod. Ind./Prod. Ind., es la tasa de crecimiento de la producción industrial.

$\Delta X / X$, es la tasa de crecimiento de las exportaciones totales.

$\triangle \mathrm{PTB} / \mathrm{PTB}$, tasa de crecimiento de producto.

Las relaciones indican que la tasa de crecimiento que experimente la producción exportable de bienes no tradicionales será la más alta de todos los sectores productivos nacionales, después se encontrará la producción industrial en general, más bajo se colocará todo el sector exportador y abajo de todos ellos, en cuanto a tasa de crecimiento real, se colocará el producto bruto.

En el esquema no se presenta cuál será la dinámica que adoptarán sectores como el dedicado a la producción de alimentos, viviendas, servicios, etc. Pues, no es que carezcan de importancia al modelo, sino que su participación es de respuesta al efecto dinamizador que le imprima el sector motor del nuevo modelo de desarrollo.

A diferencia del esquema propuesto por el Ministerio de Planificación, FUSADES privilegia una menor participación de la acción estatal, dejándole al gobierno las siguientes acciones:

- Tomar las medidas necesarias para ponerlo en marcha, ya que debe ser su promotor y facilitador, para ello deberá realizar entre otras tareas, una ley de fomento a las exportaciones para las actividades productivas especialmente las asociadas con la producción de bienes y servicios para la exportación, que la política cambiaria mantenga un tipo de cambio real, reducción del proteccionismo arancelario, eliminar los controles de precios, desarrollar una política de formación y capacitación de recursos humanos en función de la nueva pauta de 
desarrollo, etc. En otras palabras se pide que se de un tratamiento preferencial a la empresa exportadora.

- De lo anterior se deduce que es necesario dejar de aplicar "precios políticos", para que sea el mercado el que determine mediante sus fuerzas, los indices de precios relativos.

Una vez puesto en marcha el nuevo modelo y gracias a la libre determinación del mercado, conducirá a un realismo económico que redundará en la mayor utilización de la mano de obra. Al incrementar la producción de exportables no tradicionales, se mejorará la distribución funcional del ingreso a favor de los salarios en detrimento de los ingresos al capital (el último dato de que disponemos al respecto es de 1979 , de un ingreso nacional de $47,462.2$ millones se destinaron $\$ 3,302.7(44.3 \%)$ a sueldos y salarios, y $\$ 4,159.5(55.7 \%)$ como ingresos al capital). Con la crisis de la presente década lo más probable es que la composición se haya transformado favoreciendo los ingresos al capital, afirmamos lo anterior debido a que los sueldos y salarios se han mantenido congelados, los indices de empleo y subempleo se han incrementado aceleradamente, la inflación ha aumentado, todo ello incide en que del ingreso nacional se destine una parte cada vez menor a sueldos y salarios y por el otro lado se aumentan los ingresos al capital.

Antes de que se ponga en marcha el modelo propuesto por FUSADES, este ya ha comenzado con una serie de programas en forma consolidada y fuerte, que representarian la antesala o la preparación del terreno para dar inicio, cuando las condiciones políticas sean acordes para su implementación. Estos programas son los siguientes: ${ }^{8}$

- Departamento de Estudios Económicos y Sociales, analiza periódicamente y de forma sistemática la situación económica y social del pais, para dar soluciones prácticas a los principales problemas.

- Programa de Inversión y Desarrollo del Comercio Exterior (PRIDEX), que se encarga de promover la inversión extranjera y nacional en la producción de bienes y servicios no tradicionales aptos para la exportación y que al mismo tiempo generen nuevas fuentes de empleo.

- Programa de Diversificación Agropecuaria (DIVAGRO), que fomenta la producción de bienes agrícolas no tradicionales, procurando crear nuevos derivados y lineas de rubros de producción ya existentes.

- Fortalecimiento de Asociaciones (FORTAS), que contribuye al mejoramiento de la calidad administrativa, organizativa y técnica interempresarial del pais, de forma tal que puedan proveer a sus aso- 
ciados asistencia técnica, información y orientación general con el propósito de incrementar y mantener operaciones empresariales.

- Programa para la Promoción de la Pequefia, Mediana y Microempresa (PROPEMI) su finalidad es servir de apoyo al crecimiento $y$ desarrollo para los pequenos empresarios en general.

- Programa de Riego, destinado a dar asesoramiento para la práctica de riego de aquellos cultivos que lo necesiten y con mercado en el exterior, es decir, que se trata de cultivos no tradicionales.

De todos estos programas, el PRIDEX, el DIVAGRO y el de Riego vendrían a significar el comienzo o ejemplo de los nuevos productos que se deberian producir para venderse al mercado externo. Los restantes servirian de apoyo para la presentación de estudios, análisis y de calificación empresarial.

Desgraciadamente desconocemos más a fondo el contenido de cada uno de los programas, pues no sabemos cuáles son las propuestas que concretamente formulan en materia tecnológica para que seadapten a mejorar la utilización de la mano de obra en el sentido de aumentar su empleo y calificación.

\section{Quiénes están detrás de FUSADES}

En 1985 la organización interna de FUSADES estaba compuesta por una Junta Directiva de seis miembros, dieciocho Directores y diez integrantes del Comité Ejecutivo.

A continuación se presentan los nombres que conforman cada uno de los organismos directivos:

\section{JUNTA DIRECTIVA}

Roberto H. Murray Meza

Presidente

Salvador J. Simán

Vice-Presidente

Roberto Orellana Milla

Secretario

Abelardo Torres

Pro-Secretario

Ricardo Hill Argüello

Tesorero

Gustavo Cartagena

Pro-Tesorero

\section{DIRECTORES}

Guillermo Alfaro Castillo

Luis Andreu

Carlos Patricio Escobar

Ramsey, L. Moore

Eduardo Núnez I.

Giannetto Paggi 
Enrique García Prieto

Roberto Hill

Juan Vicente Maldonado

Roberto Mathies

Leonel Mejía

Eduardo Menéndez
Carlos Palacios

Abraham Rodriguez

Mario Luis Velasco

Arnoldo Villafuerte

Nassin Yarhi

Jorge Zablah Touché

\section{COMITE EJECUTIVO}

Roberto H. Murray Meza

Salvador J. Simán

Roberto Orellana Milla

Ricardo Hill Argüello

Eduardo Núnez I.
Gustavo Cartagena

Mario Luis Velasco

Giannetto Paggi

J. Eduardo Castañeda V.

Antonio Cabrales

Los 34 puestos directivos son ocupados por 27 personas, solamente tres miembros del Comité Directivo no están en los organismos anteriores. Del total de personas resalta que la mayoría tiene intereses económicos ligados a la industria y al sector financiero, y sólo unos pocos tienen fuertes intereses agrarios aunque combinados, pues no aparecen como exclusivos terratenientes. Es importante detectar lo anterior pues dentro del pensamiento de la nueva derecha, tal como ya se dijo, se le da prioridad a las actividades productivas dinámicas que consideren el realismo económico para evitar desajustes en el mercado de factores.

Al realizar un recuento de las principales actividades económicas de los integrantes de la Junta Directiva, que se presentan en la obra de Eduardo Colindres "Los. Fundamentos Económicos de la Burguesía Salvadorena", encontramos que su Presidente, Roberto H. Murray Meza aparece como accionista en varias juntas directivas de empresas, como la Corporación Desarrollo S.A. (CORDESA), Embotelladora Tropical S.A., Embotelladora Salvadorefía (Coca Cola), y en Propiedades e Inversiones S.A.

El Vicepresidente, Salvador J. Simán en las juntas directivas de: Patricia S.A. de C.V., Hilaturas de C.A. (HILCASA), Los Nogales S.A., Inversiones Salvador S.A., y como accionista en José J. Simán e hijos S.A. de C.V. y en Inmobiliaria San José y en Inversiones Diversas; en cuanto a cargos en agrupaciones corporativas se encuentra como tesorero y presidente de la Cámara de Comercio e Industria de EI Salvador.

El Secretario, Roberto Orellana Milla, en la junta directiva de Fo- 
mento de Inversiones S.A. (FOMINCO); como accionista en la Companía de Fomento de Inversiones S.A. (COFISA), en Productos Botánicos S.A. y en Panes S.A. (PANESA).

El Pro-Secretario, Abelardo Torres, sólo se encuentra en cargos de organismos corporativos como gerente y asesor en la Asociación Salvadorefia de Industrias (ASI) .

El tesorero, Aicardo Hill Argüello, en las juntas directivas de la Companía Financiera Comercial, en Proyectos Generales S.A., en Companía de Inversiones S.A., en Parque Industrial y Comercial Desarrollo S.A., en ADOC, y en J. Hill y Cia.

Por último el Pro-Tesorero, Gustavo Cartagena como accionista en la empresa constructora ARCO S.A.

Entre los integrantes de la Junta Directiva, encontramos personas vinculadas con familias que tienen intereses en el agro, como son Roberto Murray Meza y Ricardo Hill, sin embargo, ellos en lo particular están dedicados a otras actividades, donde sobresalen intereses de la gran industria, como el caso de las embotelladoras y en actividades financieras. El resto de la Junta Directiva, el asiento principal de sus actividades es la industria, comercio y sector financiero.

Del listado de intereses que tienen los miembros directivos no es de extranar que la propuesta para el nuevo modelo descarte los esquemas de desarrollo anteriores, basados en la agricultura de exportación y la sustitución de importaciones.

Desde luego, resulta un tanto dificil explicar la aparente contradicción que podría generarse entre intereses familiares, ante todo en la producción de café, que podrian tener algunos miembros de FUSADES con el modelo propuesto. La respuesta puede ser que en primer lugar, buena parte del contlicto social que vive el pais en la presente década es ocasionado por la excesiva concentración de riquezas en pocas manos, originada de las ganancias que genera la agroexportación, pero además las utilidades que han venido a menos, no es de extrañar que la producción de café ha disminuido en la presente década aproximadamente $30 \%$, el algodón y azúcar han dejado de exportarse; por otra parte comparativamente con otros sectores de la economia, el café ha venido perdiendo primacia, tal como se indicó anteriormente, pues en la presente década ha sido superado por el sector comercial como generador de utilidades. Dentro de la lógica capitalista el que se aferra al pasado y no tiene capacidad innovadora tiende a ser desplazado en los momentos de crisis y en algunos casos a ser sustituido o simplemente eliminado y quien no tenga capacidad 
previsora o de adelantarse a los acontecimientos puede más temprano que tarde ser simplemente un acontecimiento histórico sin posibilidades de desarrollo futuro. De ahí que los miembros de la oligarquía que se encuentran en FUSADES pueden ser catalogados como los visionarios de este sector, que han comprendido la necesidad de cambiar su eje de acumulación, al igual que lo fueron los que propugnaron la industrialización via sustitución de importaciones, o bien los cafetaleros del siglo pasado que sustituyeron al aniil.

\section{Diticultades al modelo de FUSADES}

El modelo definido como fomentador de exportaciones no tradicionales pretende hacer de El Salvador un pais maquilador, al igual que ahora lo son Corea, Taiwan, como también otros Estados del Sudeste asiático, Hong Kong, Tailandia, Indonesia, Singapur, Ceilán, etc. Se podrian enumerar a más, pero no se trata de agotar todos los paises que en estos momentos están dedicados a la maquila, sino únicamente de indicar que el modelo de FUSADES entrará con un retardo al concierto mundial de la maquila, lo cual no es una novedad para El Salvador que siempre ha implementado de manera imitativa modelos que otros países han desarrollado con anterioridad.

La imitación de modelos de desarrollo no se puede calificar a priori como benigna o maligna, pues esto requiere que se realice una diversidad de estudios sobre la conveniencia o no de que se implemente dicho esquema por un nuevo país. En primer lugar se debe realizar una investigación a fondo sobre el mercado internacional de los bienes que se van a producir, aunque estos no se indican claramente en la propuesta de FUSADES, se puede deducir que se refieren a bienes manufacturados donde predomine el uso de mano de obra, donde los paises ya mencionados del Sudeste asiático, llevan la batuta dentro de los paises subdesarrollados maquiladores, to cual implica que tienen buena participación en la oferta mundial, de ahi que El Salvador tendria que entrar a competir en un mercado que ya se encuentra dominado y saturado.

Por otra parte, el destino o mercado de la producción de bienes maquilados se concentra en los paises desarrollados, mismos que están pasando por una crisis de redefinición capitalista, la cual los ha conducido a la instrumentación de medidas proteccionistas y neoproteccionistas que dificultan la exportación que hacia ellos pueden realizar los paises subdesarrollados.

La crisis monetaria internacional, aunada a las dificultades crecientes que está imponiendo la deuda externa al Tercer Mundo, obligan a estos 
paises a buscar divisas fuertes para cubrir los compromisos que la deuda exige, para ello los países tercermundistas están empefiados en lograr conseguir balanzas comerciales superavitarias para tener divisas, que puedan dedicar al pago de su deuda externa, esto conduce a que en estos paises se de una abierta competencia por lograr mercados para sus productos, lo cual lleva a un desenfreno en el mercado internacional de manufacturas provenientes de las regiones subdesarrolladas que crea saturaciones y por consecuencia la reducción del precio internacional lo cual conduce a menos ganancias por esfuerzo realizado tanto para el empresario y para el país.

Sobre el aprovechamiento de la ventaja comparativa que tiene El Salvador gracias a su abundante mano de obra, diversos estudios recientes han llegado a determinar que dicha ventaja podría ser el bajo costo de la mano de obra, lo cual se va perdiendo debido a la introducción de procesos productivos robotizados que incrementan en forma notable la productividad de los obreros en los paises industrializados, que se traduce en incrementos en la tasa de ganancia a pesar de los mayores salarios que se pagan en los paises desarrollados.

Al respecto, un trabajo de Peter F. Drucker aparecido en marzo de 1988 , señala que el nivel salarial ya no es determinante para definir la orientación de la producción y comercio internacionales. Las ideas principales que maneja son las siguientes:

- Los niveles salariales para los obreros se están volviendo de forma creciente irrelevantes en la competencia mundial, pues adquieren mayor preponderancia aspectos como calidad, disefío, servicio, innovación, comercialización, ya que los salarios como elementos del costo directo, gracias a los procesos tecnológicos implementados en el área de la producción, disminuyen su participación.

- La razón que fundamenta esto es que el trabajo obrero ya no representa lo suficiente del total de costos para dar a los salarios bajos una ventaja más competitiva. Hazón pues, de que existe una regla, ya aceptada o generalizada, para que la producción importada pueda ser competitiva por regiones de origen, debe ser entre $5 \%$ y $7.5 \%$ más barata que la producción cercana para recompensar los considerables costos de traslado. $Y$ si los costos salariales caen por debajo de $15 \%$ del total, se requiere de un diferencial salarial de $50 \%$ dada la misma productividad laboral, para compensar los costos de distancia.

Ahora bien, esto podría ser una ventaja para El Salvador dada su mayor cercania con Estados Unidos que la de los paises del Sudeste 
asiático, pero respecto de Europa dicha ventaja se pierde. Si consideramos que Estados Unidos importa menos que Europa en su conjunto, en ese caso las posibilidades de acceso al mayor mercado capitalista regional, se ven disminuidas y se tendria que seguir contando con que el mercado estadounidense seguiría siendo el principal y las posibilidades de diversificar mercados tendria dificultades de realizarse. Pero la situación no para ahí, pues al interior de Estados Unidos los costos salariales van cayendo en importancia, asi tenemos que a fines de la década pasada representaban alrededor de $27 \%$ del total, en estos momentos se colocan en $18 \%$ y están bajando rapidamente a medida que la productividad se eleva a buen paso.

Por ejemplo una empresa que actualmente opera a un costo salarial por arriba del $17 \%$ se encuentra atrasada, sintiendo la presión, derivada del alto porcentaje que significan sus costos salariales, si es que desean continuar siendo competitivas debe reconvertirse industrialmente, para encontrar procesos productivos que eleven la eficiencia de la mano de obra.

Una consecuencia directa que se deriva de la reconversión para el caso estadounidense, se ha iniciado en forma paulatina y lenta un retorno de inversiones que se encontraban en el extranjero aprovechando la abundancia y baratura de la mano de obra que tienen los paises tercermundistas.

Lo paradójico para los países maquiladores o que esperan llegar a serlo, es que actualmente la tendencia generalizada de la dirección del comercio internacional cambie de sentido, pues Europa, Japón y Estados Unidos están transfiriendo su producción, misma que antes importaban, al exterior y hacia las naciones subdesarrolladas. Esta tendencia significa una competencia creciente entre manufactureros de los paises desarrollados, dejando relegados a los países maquiladores tercermundistas ${ }^{9}$.

La derivación de lo que podria acontecer a El Salvador de ponerse en práctica el modelo propuesto de FUSADES, de acuerdo con el razonamiento dado, lleva a concluir que su viabilidad como modelo alternativo de desarrollo es muy cuestionable. Se podrian presentar otros elementos técnicos que apuntarian en el mismo rumbo, como serian las siguientes preguntas ¿Qué tipo de tecnología requiere su puesta en marcha y donde se consigue? ¿Si existe capacidad interna para generar el tipo de tecnología que sea congruente con la utilización de un proceso productivo que emplee más mano de obra, o si siempre habrá que importarla de los paises productores o generadores de tecnologia? ¿Si los paises donde se produce la tecnología están más interesados en 
desarrollar aquella que ahorre mano de obra y que al mismo tiempo le eleve la productividad, puede este tipo de tecnología servir a los intereses del modelo FUSADES para que logre convertirse en determinante dentro del capitalismo salvadorefio? Las respuestas que se den a éstas y otras interrogantes servirán para determinar la viabilidad, que pueda tener la propuesta de FUSADES en términos técnicos.

Lo más peligroso de la propuesta no es el modelo económico en sí, si no la derivación del régimen político que se requiere para poder implementarlo, de acuerdo con los ejemplos de aquellos paises que con relativo éxito han emprendido un esquema de desarrollo basado en la exportación de bienes manufacturados, mencionan a Taiwan y Corea del Sur, al respecto indican que "Las experiencias obtenidas en las economias de paises pequefios, recientemente industrializados, constituyen un estimulo para paises que, como El Salvador, enfrentan graves desequilibrios financieros que limitan su crecimiento. Con pocas posibilidades de superarlos con las modalidades actuales, estos paises emprenden nuevas estrategias. Para el caso, Taiwan, Corea del Sur y otros que han logrado resultados concretos después de la adopción de las nuevas estrategias. Tales paises presentan dos caracteristicas: son relativamente pobres en recursos naturales y relativamente ricos en recursos humanos. Tanto en Corea como Taiwan, existen antecedentes coloniales y su abundante fuerza de trabajo laboral se ha visto complementada por una tradición cultural de niveles favorables de alfabetización y calidad educacional. Las metas originales de reconstrucción y estabilización en estos paises, fueron sustituídas por metas de crecimiento económico ... la promoción de exportaciones ... fue facilitada por acciones directas del gobierno, tales como el establecimiento de zonas de procesamiento de exportaciones y la devolución de aranceles de importación sobre las materias primas utilizadas en la producción exportable".

"Concretamente, el papel del gobierno en el campo económico fue el de promotor de la nueva estrategia, en el sentido de crear las condiciones y facilitar el desenvolvimiento del sector privado ${ }^{10}$. Es decir, que al gobierno le asignan un papel protagónico para que el modelo se pueda implementar; revisando el tipo de gobierno que dichos paises tienen, llegamos a la conclusión que son dictatoriales.

Al respecto, sobre Corea del Sur, su historia política registra que después de la derrota de Japón, en la Segunda Guerra, Corea fue dividida en dos territorios, en 1948 fue electo presidente Syngman Rhee, que duró en el poder 14 años durante los cuales se hizo reelegir tres veces sometiendo a dura represión a la sociedad sudcoreana. En 1963 
es electo presidente el general Park, su gobierno fue impopular ejerció el poder del modo más riguroso e implacable, bajo el carácter de un Estado policial; fue durante su gestión, misma que duró varios años pues fue reelecto por cuatro períodos consecutivos, es que se produjo el auge económico de Corea del Sur, situación que fue posibilitada por el apoyo que recibió de las Naciones Unidas y del gobierno estadounidense. Dicho esquema de industrialización ha sido tomado como "modelo" para el Tercer Mundo, olvidando que para ello fue necesario un régimen autoritario, que gobernó bajo estado de sitio desde 1949 hasta 1982.

En cuanto a Taiwan, la situación no es muy disimil de la de Corea, de 1949 a 1975, Chiang Kai-Shek gobernó bajo un régimen autoritario de excepción, a su muerte asumió la presidencia su hijo y mantiene el mismo tipo de gobierno; sólo el partido oficial es reconocido, el Kuomintang, las leyes de Taiwan castigan con la pena de muerte a las personas que acusen públicamente al régimen, lo cual no es de extranar, pues se gobierna bajo permanente ley marcial'11.

Los dos ejemplos que se dan, tienen una particularidad, son gobernados bajo regímenes autoritarios, de ellos surge una pregunta ¿para el caso salvadoreño, en el modelo de FUSADES, será también necesario que se desarrolle este mismo tipo de gobierno para que pueda tener viabilidad? Además otros paises que han seguido el mismo tipo de desarrollo también han tenido la misma forma de régimen, tal es el caso de Singapur, donde el primer ministro está desde 1959; el caso de Hong Kong que carece de gobierno propio, siendo el gobernador nombrado desde Inglaterra.

Por otra parte, si se menciona en la propuesta de FUSADES, que se logrará una distribución funcional del ingreso nacional, que comparativamente con la existente, favorecerá al monto salarial, en detrimento de los ingresos al capital, hasta qué punto dicha distribución podrá favorecer a los trabajadores en forma efectiva, pues lo que se necesita es elevar el salario real a niveles que superen la línea de pobreza de la gran mayoría, esto si seria aceptable y no únicamente referirse a la distribución funcional, sino que se hace imprescindible mejorar la pésima distribución del ingreso que existe por tramos de ingreso percibido.

\section{Qué posiciones tiene la nueva derecha esładounidense res- pecto del proceso salvadoreño}

Se desconoce una postura de la Nueva Derecha de los Estados Unidos, lo cual no implica que si tengan definiciones al respeto. Son tan variadas las organizaciones que promueven el pensamiento neoliberal en dicho país, que van desde centros de análisis, conocidos como 
"think-tanks" (tanques de pensamiento) hasta personeros del gobiemo, entre los que detacan: EL CEIS (Center for Estrategic and International Studies) de Georgetown que se ha especializado en asuntos extranjeros y ha producido buen número de funcionarios para este campo. Entre ellos, Ray S. Cline, que fue director de la CIA, posteriormente, Director Ejecutivo del programa de estudios del poder en el mundo; y Roger Fortaine, que después fue trasladado al AEI.

EI AEI (American Enterprise Institute) que cuenta con un equipo de académicos y politicos dedicados a hacer propaganda sobre las bondades del sistema de libre empresa. Se le considera una de los think-tanks, data de 1943. Durante anos se estudiaron ahi las formas de proteger los intereses empresariales norteamericanos de Latinoamérica.

El Hoover's Institution on World Revolution and Peace, de la Universidad de Stanford. Su objetivo inicial fue el construir un gran archivo que debería convertirse en punto de referencia obligado para los futuros estudios sobre la URSS con el fin de demostrar lo diabólicas que son las doctrinas de Marx, ya sean el comunismo, el socialismo, el materialismo económico, el ateismo, y proteger de esa forma el sistema norteamericano de vida (american way of life) de tales ideologías, de sus conspiraciones, etc.

La Heritage Foundation, es de las más recientes, aparece muy vinculada al presidente Reagan. Su trabajo editorial es muy fuerte, en un solo año, 1980, publicó 100 libros. Para acelerar el giro de Estados Unidos a la derecha lo más rápido y drásticamente posible, elaboró una agenda con análisis, soluciones, diagnósticos, previsiones y terapias, y la ofreció a la administración Reagan.

Diversas personalidades de la política estadounidense destacan entre los principales defensores y abanderados de la Nueva Derecha, Jeane Kirkapatrick, Edwin Meese, Ronald Reagan, Henry Kissingery otros. De ahi que se diga que la administración Reagan, al menos durante su primer mandato, estuvo dominada por la ideologia neoliberal y para la segunda influenciada.

De las posiciones que sobre determinadas coyunturas salvadoreñas ha tenido la Casa Blanca, se puede inferir cual es la postura de la Nueva Derecha.

El Informe Kissinger destaca que se debe disminuir el excesivo poder concentrado en la oligarquia, manifestando incluso que en aquellos países centroamericanos donde se han iniciado procesos de reforma agraria, como en El Salvador, se deben profundizar y en ningún mo- 
mento detenerse y mucho menos darles marcha atrás. Lo cual es indicativo de que se oponen a las viejas estructuras de dominación oligárquicas por considerar que es un modelo agotado que lejos de haber dado soluciones verdaderas a los problemas que de antafio aquejan a la sociedad salvadoreña, los han venido acarreando y que son causa y prolongación de la crisis en El Salvador, de ahi que sea necesario reencausar al capitalismo salvadorefio mediante la implementación de un nuevo modelo que dé mayor racionalidad y que a la vez sea modermizante del aparato productivo salvadoreño.

Destaca también el veto que la Casa Blanca ha impuesto al partido ARENA para que pueda tener una efectiva preponderancia en el sistema politico salvadorefio. Desde las elecciones de Asamblea Constituyente, en 1982, han bloqueado a dicho partido, en esa ocasión impidieron que Roberto D'Aubuisson fuera presidente provisional de El Salvador (tampoco le dan visa para que visite suelo estadounidense). En las elecciones presidenciales de 1984, la CIA apoyo abiertamente la candidatura de Napoleón Duarte, desplazando asi a su contrincante Roberto D'Aubuisson.

En las elecciones efectuadas el 20 de marzo de 1988, para elegir diputados de Asamblea Legislativa, de nueva cuenta aparece una especie de veto, esta vez dificultando que ARENA pudiera obtener la mayoría absoluta de diputados; la situación se resolvió cuando ARENA "compró" a un diputado del PCN y posteriormente la Corte Suprema de Justicia dictaminó otorgarle un diputado que estaba en disputa. En todo este periodo que transcurrió, las negociaciones fueron intensas, ARENA se vio en la necesidad de cambiar de imagen y discurso; D'Aubuisson fue relegado como figura política, incluso ni tan siquiera fue nombrado dentro de la directiva de la Asamblea, situación que resulta dificil de entender, que quién fuera Presidente de la Asamblea Constituyente (1982-83) en la actualidad sea un simple diputado, asimismo, que fuera nombrado Coordinador de la Comisión Legislativa revisora de la Reforma Agraria, donde se ha visto en la necesidad de afirmar que es necesario hacerla eficiente, cuando a principios de la presente década fue uno de sus más acérrimos opositores, incluso su meteórico ascenso como figura representativa de los intereses oligárquicos, se dió precisamente porque D'Aubuisson prometió darle marcha atrás a todas las reformas emprendidas entre 1979 y 1980.

Como candidato presidencial de ARENA, fue nombrado Alfredo Cristiani, de quien se dice que es un empresario que tiene ideas menos recalcitrantes que D'Aubuisson, y que a la vez liderea una fracción "moderada" dentro de ARENA; mientras que el ex-mayor lo es de la 
fracción considerada "dura"

En las últimas elecciones que fueran ganadas por ARENA y que dieran a Cristiani como presidente electo, éste se ha comprometido con el presidente Bush de que D'Aubuisson no irá como miembro del gabinete y que continuará como diputado.

Asimismo, el gobierno de los Estados Unidos ha venido apoyando en todos los aspectos a Napoleón Duarte, incluso impidiendo que le den un golpe de estado por parte de seclores pro-oligárquicos. La ayuda económica y militar es cuantiosa, el apoyo de planes y proyectos es impresionante.

Para Robert Wesson, del Hoover's Institution, en el artículo que escribe denominado "El Salvador: para bien o para mal", señala que tanto la derecha como la izquierda, ven a Duarte como una marioneta de los Estados Unidos y dirigen la mayoria de sus ataques verbales contra el presidente y no contra las clases altas de la oligarquía tradicional. Por su lado, las clases altas consideran a Duarte un enemigo, socialista, llegando incluso a manifestar que es más peligroso que la guerrilla, asi como el principal responsable de la mayoria de males que aquejan al pais. Señala también que para la Embajada de los Estados Unidos no existe otra altemativa posible, para el caso salvadoreño que no sean un gobierno democristiano, incluso espera que para las elecciones presidenciales de 1989, de nuevo sea el PDC el que triunfe, no seria remoto que de nuevo la CIA apoye a dicho partido. De ser asi, se estaría legitimando la democracia cristiana como la alternativa política más viable para implementar el proyecto de la Nueva Derecha en El Salvador, habida cuenta que el proyecto económico del PDC contenido en el documento elaborado por el ministerio de planificación, - cuando estuvo al frente de él Fidel Chávez Mena, el candidato presidencial del PDC, que se denomina "Bases Metodológicas para la Elaboración del Plan de Desarrollo 1985-1989" - tiene más coincidencias que discrepancias con el modelo propuesto por FUSADES, siendo por tanto un modelo que cuenta con el agrado de la Casa Blanca, no así el de ARENA, que es un regreso al pasado.

\section{Conclusiones}

- De los planteamientos que hace la clase capitalista salvadoreña, es el de FUSADES el que más se asemeja a los de la Nueva Derecha, si bien es cierto que el grupo empresarial salvadoreño aclara que su propuesta es ante todo de carácter económico, pero en ella va implícita la posición sobre el papel que el .Estado debe jugar, asi como el de las clases trabajadoras, etc. siendo todas ellas muy coinci- 
dentes con los postulados de la Nueva Derecha.

- Los grupos corporativos de la empresa privada salvadorefia, son legítimos representantes de las posiciones de la Vieja Derecha, de ahi que no sorprenda que FUSADES tenga una estrategia de penetración hacia dichos sectores, con el fin de venderles la idea y conveniencia del nuevo modelo que proponen.

- Las personas que estan detrás del proyecto de FUSADES, tienen sus intereses o inversiones principalmente en los sectores industrial y financiero, teniendo relegados, si es que los tienen, intereses en la agroexportación.

- El modelo propuesto de crecimiento hacia afuera tiene en estos momentos grandes dificultades de éxito o de llegar a convertirse en un modelo alternativo de desarrollo para EI Salvador, pues situaciones internacionales como la fuerte competencia en los mercados de los productos maquilados, hace dificil la inserción de nuevos paises a competir y a obtener resultados positivos, no sea que se tenga que recurrir al abaratamiento ficticio, vía subsidios, para poder hacer competitivos los productos salvadoreños, al mismo tiempo, la crisis por la que estan pasando las economias desarrolladas, que son el principal mercado donde se colocan los bienes maquilados, hace que dichos paises restringan sus importaciones mediante medidas proteccionistas o neoproteccionistas.

- La tecnología que se requiere para poder reconvertir el aparato productivo salvadoreño entra en contradicción con uno de los objetivos básicos del modelo propuesto, que es precisamente el poder invertir la relación de la distribución funcional del ingreso para que la masa salarial supere a los ingresos al capital, pues al requerirse mayor productividad de la mano de obra, ésta solo puede lograrse con tecnologia que la sustituya. Otro aspecto importante es que los principales centros generadores de tecnologia, como son los paises desarrollados estan más interesados en desarrollar métodos productivos menos intensivos en mano de obra, de alli que para que el modelo pueda tener viabilidad requiere que al interior de EI Salvador se genere la tecnologia apropiada para lograr los objetivos propuestos.

- Pero aún suponiendo que las dificultades técnicas puedan solventarse y que no ofrescan ninguna dificultad, queda un serio escollo o una gran interrogante que responder y es el tipo de régimen que se requiere para que un modelo de desarrollo de dicho tipo pueda salir adelante. En prácticamente todos los países que han iniciado un 
crecimiento hacia afuera basado en la industria no tradicional, se ha requerido de un régimen político fuerte $y$ autoritario que ha sido capaz de domesticar a la población trabajadora, los casos de Taiwan y de Corea del Sur hablan por sí solos al respecto. Para el caso salvadoreño la pregunta es que ¿si se requerira del mismo tipo de régimen para que pueda ser efectivo el modelo?. De ser positiva la respuesta, entonces de que ha servido la guerra, sus muertos, su secuela de destrucción y de calamidades si lo que va a dar de hecho es caer de la cacerola a las llamas.

- La Nueva Derecha estadounidense esta interesada en la promoción de sus planteamientos en la situación salvadoreña, el gran empeño en ello es palpable en el apoyo fuerte y decidido a los planes contrainsurgentes, en las medidas que han apoyado para debilitar a la vieja derecha(reforma agraria, nacionalización del comercio exterior, restarle poder político, etc), en asesoramiento técnico, en apoyos monetarios directos, etc., como producto de todo ello, El Salvador se ha colocado en el cuarto lugar de paises que reciben ayuda por parte de Estados Unidos.

\section{Notas}

1. LAZO, Francisco. La Estrategia norteamericana y la geopolítica de América Central en "América Central: Geopolitica y Crisis Regional". Cuaderno de Trabajo № 8, CINAS México, septiembre de 1986. Pág. 25.

2. LAZO, Francisco. "La factibilidad de implementar un programa de estabilización y reactivación económica en una economla de guerra. El caso de El Salvador: 1986". Tesina para obtener el grado de maestro en Economia y Política Internacional. CIDE, México, julio de 1986. Pág. 19 y 80.

3. Ibid. Pág. 44

4. CINAS. "Hacia la creacón de un movimiento social de derecha. El caso de las clases dominantes". Cuaderno de divulgación № 3. México, agosto 1987.

5. Ibid.

6. FUSADES. "La Necesidad de un Nuevo Modelo Económico para EI Salvador. Lineamientos generales de una estrategia" 1985. San Salvador.

7. RODRIGUEZ L. Ralael A. entrevista concedida a la revista SEMANA, que aparece en el número 7 de diciembre de 1987, vol. 2

8. Ibid.

9. DRUCKER, Peter F. "El Nivel Salarial ya no es relevante en la Competencia Mundial, Disminuye en Relación con los Costos". Excélsior Sección Financiera, 23 de marzo de 1988. México.

10. FUSADES. Op, cit.

11. Guía del Tercer Mundo. México, D.F., Editora Tercer Mundo. 


\section{Anexo}

\section{SUBSISTEN 2 PAISES EN SUDCOREA; UNO POBRE Y OTRO RICO}

- Bajos Salarios y Larga Jornada Laboral, la Vieja Cara

- Hacinamiento y Muchos Accidentes Enmarcan la Fábrica

- Se Abusa y se Explota al Trabajador en la Industria

\section{Por Susan Chira, de The New York Times}

ANYANG, Sudcorea, 7 de abril. Después de ocurrido el siniestro en una fábrica textil, quedan los recuerdos de mujeres que trabajaron y murieron en Green Hill Textile Co.

El fuego comenzó a finales de marzo mientras que 28 jóvenes trabajadoras textiles dormlan en la fábrica, que sirven también de dormitorio en este suburbio de Seúl. Debido a que las puertas que conducian a las escaleras estaban cerradas y repletas de suéteres tejidos por las mujeres en ese día, solo escaparon unas cuantas. Murieron 22 trabajadoras.

Pequeñas fábricas como ésta, atestadas de mujeres que trabajan largas horas a cambio de un bajo salario en tristes barrios, abundan todavia en Sudcorea. Forman la otra parte de la economla en auge que produce carros Hyundai y que apila excedentes comerciales con Estados Unidos.

Esta otra Sudcorea existe junto con las relucientes nuevas fábricas y rascacielos. Es el país de chozas en las montañas y de pregoneros que jalan carritos cargados con briquetas de carbón vegetal y mujeres como las de Green Hill Textile Co., que duermen en cuartos sin ventanas a unos cuantos pasos de máquinas de coser.

Las mujeres que murieron quemadas provinieron del campo en busca de trabajo y de las bondades de la vida citadina. La mayor parte de obreros en las fábricas textiles, de calzado y electrónicas son jóvenes mujeres campesinas. Las que no tiene suerte para trabajar en pequeñas fábricas, un poco mejor en comparación con las factorlas donde se explota al obrero.

En un país con una alta tasa de accidentes industriales, donde el salario promedio por hora para todas las industrias es de 1.75 dólares y el promedio de hora por semana trabajadas asciende a 57, estas mujeres jóvenes reciben salarios muy bajos y soportan duras condiciones laborales. En 1985, los accidentes industriales cobraron 1,728 vidas de trabajadores y provocaron accidentes en 140,091 personas. Según el Ministerio de Trabajo; las cifras comparativas para Estados Unidos en ese año fueron de 3,420 víctimas y 5,381,700 lesionados. Un sinnúmero de accidentes en Sudcorea no se reportan ante las autoridades. 


\section{NO RECIBIERON MALOS TRATOS}

Las trabajadoras en Green Hill Textile Co, no recibieron malos tratos, por lo menos con base en las normas de este pais. Chang Won-Kill policla de guardia de 63 años, amigo de muchas de las trabajadoras dijo que normalmente comenzaban su día de trabajo a las 8:30 y que trabajaban hasta las 19:30 p.m.

Sin embargo, los dlas que tenlan que apresurarse a cumplir pedidos $-y$ hubo un sinnúmero de ellos - trabajaron en las máquinas hasta las 22023 horas. Contaban con 20 minutos para almorzar, 30 minutos en un buen día y se les permitía faltar durante dos domingos al mes. Por su trabajo recibieron entre 270 y 340 dólares mensuales.

La fábrica, ubicada entre un billar, un restaurante y una iglesia, en el segundo piso un centro comercial de una calle importante, no contaba con autorización para operar. Los vecinos del lugar dijeron que el dueño, de 44 años, Lee Pung-won, luchó para establecer el negocio y que no contó con los medios para hacerlo legalmente.

Chang, el guardia comenta que el propietario trala alimentos y pastel para las jóvenes trabajadoras cuando tenlan que trabajar tarde. "El señot Lee se comportaba con ellas como si fuera su hermano o su padre", manifestó Chang Joovong, quien asiste el restaurante contiguo y quien a menudo sivió el almuerzo a las mujeres que trabajaron en ese lugar. "Parecieron tener buenas relaciones como si fueran una familia".

Otras muchas mujeres obreras, deben enfrentarse a situaciones peores. No lejos de Green Hill Textile Co., existe un centro administrado en forma privada para trabajadores de fábricas, un lugar en el que pueden solicitar asesorla asi como recámaras limpias y a precios bajos. Los miembrso directivos del centro, que prefieren que sus nombres no sean publicados por temor a entrentarase a funcionarios de gobierno y gerentes de fábricas locales, mencionaron una larga lista de problemas enfrentados por los trabajadores.

Muchos de ellos comienzan sus empleos sin saber cuales serán las condiciones salariales; no se les comunica o no cuentan con la preparación requerida para leer los caracteres chinos que se imprimen en los contratos. Muchos de ellos están subalimentados, ya que solo tienen tiempo para alimentarse una sola vez al dla. A menudo presentan enfermedades de los ojos o de la piel u otros problemas, y los propietarios de las pequeñas empresas pueden violar las leyes que los obligan a pagar seguro por accidente o enfermedad. Los gerentes pueden cancelar vacaciones prometidas o requerir a los trabajadores laboren tiempo extra sin enterarlos de antemano; de no acatar sus disposiciones pueden ser despedidos.

\section{VICTIMAS DE LOS USUREROS}

Efectivamente, un sinnúmero de trabajadores reciben tan bajos sueldos que requieren trabajar tiempo extra para satisfacer sus gastos. Una mujer en el 
centro gana 5.80 dólares al dia. Si trabajara semanas de 6 dlas y ocho horas cada uno, tendrla un salario de 121.20 dólares al mes, cifra insuficiente para pagar renta y alimentos. Una gran cantidad de obreros auxilian a sus familias en provincia y son victimas de los usureros cuando sus salarios bajan en forma abrupta.

Algunos trabajadores describen que la vida en la ciudad no es como soñaron que podrla ser. "Pensé que podría ganar mucho dinero y llevarlo a casa, pero la situación es diferente" dijo una obrera de 22 años, llamada Kim.

Kim trabaja en una fábrica electrónica que prueba semiconductores para computadoras por aproximadamente 5 dólares diarios.

Normalmente trabaja doce horas al dia, con tres dias de descanso al mes. Tiene mayor agrado de trabajar en su empleo actual que en el anterior en una fábrica de ropa. En ese lugar, dijo, tuvo que trabajar de pie. Ahora puede sentarse. Los días de descanso, platica con sus cuatro compañeras de cuarto o practica balonesto y tenis de mesa. Sin embargo, extraña la vida en la granja de su madre. "Todo es verde en la provincia, y se encuentra todo tipo de flores en el lugar", dijo "No se les puede ver aquí". Lo último que se compró Kim con su sueldo fue helechos de maceta.

Pese a las dificultades de la vida un sinnúmero de mujeres obreras en la ciudad, un trabajo en una fábrica es la única opción. Pueden enviar parte de su salario a sus padres, satisfaciendo así un sentimiento profundamente arraigado de obligación para con la familia. Algunas de las mujeres destinan las tardes para asistir a las escuelas nocturnas en pos de un diploma escolar, requisito previo para superarse en Sudcorea, pais consciente de la educación. Si trabajan arduamente y viven frugalmente, tal vez ahorren lo suficiente para su dote matrimonial.

En días recientes, todavía había charcos de agua de las mangueras de bomberos en Green Hill Textile Co., Chang, el guardia de seguridad, caminó entre los escombros. Perdida entre ellos, junto a álbumes y cartas, así como roperos de vinil llenos de ropa, se encontró un recordarorio final en Green Hill Textile Co.: una libreta de ahorros.

Excélsior 8 de abril de 1988. 